\title{
Cyclohexadiene-trans-diols as versatile starting material in natural product synthesis: short and efficient synthesis of iso-crotepoxide and ent-senepoxide
}

\author{
Volker Lorbach, ${ }^{a}$ Dirk Franke, ${ }^{a}$ Martin Nieger ${ }^{b}$ and Michael Müller*a \\ a Institute of Biotechnology 2, Forschungszentrum Jülich GmbH, 52425 Jülich, Germany. \\ E-mail:mi.mueller@fz-juelich.de; Fax: (+49)2461-61-3870 \\ ${ }^{b}$ Department of Inorganic Chemistry, University of Bonn, Gerhard Domagk Str. 1, 53121 Bonn, Germany
}

Received (in Cambridge, UK) 14th November 2001, Accepted 21st January 2002

First published as an Advance Article on the web 7th February 2002

A new synthesis of ent-senepoxide and iso-crotepoxide starting from microbially produced (+)-trans-2,3-dihydroxy2,3-dihydrobenzoic acid via regio- and stereoselective epoxidation is described.

Highly functionalized cyclohexane derivatives like conduritols and cyclitols have attracted considerable attention because of their useful biological activity. ${ }^{1}$ Cyclohexadiene-cis-diols (cisCHD), substituted at the diene unit, have been established as valuable chiral building blocks in the synthesis of such substances, in particular because of their good accessibility. ${ }^{2}$ Functionalized cyclohexadiene diols possessing a trans-configuration of the two hydroxy groups (trans-CHD) have not been established as chiral building blocks in syntheses in the same way so far. Due to the difficult access to enantiomerically enriched trans-CHD by multistep syntheses 3,4 or starting from cis-CHD through inversion of configuration, ${ }^{5}$ they have been relatively rarely used in natural product synthesis.<smiles>[R]C1CC=CC(O)C1O</smiles>

cis-CHD

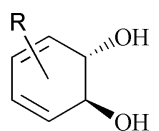

trans-CHD
Recently, we have shown that trans-CHD are also available in multigram scale by cultivation of recombinant Escherichia coli cells. ${ }^{6}$ This offers the possibility of establishing new short and efficient synthetic strategies to biologically active and pharmaceutically interesting compounds.

In order to demonstrate the potential of trans-CHD as versatile chiral building blocks, we present investigations towards regio- and stereoselective epoxidation of either one or both olefinic double bonds and the usage of this reaction in the synthesis of ent-senepoxide $\mathbf{1 2}$ and iso-crotepoxide $\mathbf{1 5}$ (1,2,3,4-tetra-epi-crotepoxide).

$(2 S, 3 S)$-trans-Dihydroxy-2,3-dihydrobenzoic acid $\dagger$ $(2,3$-trans-CHD; 1$)$ occurs in E. coli as a metabolite derived from the shikimate-chorismate pathway. Using techniques of metabolic engineering microbial producer of 1 could be obtained. ${ }^{6}$ Enantiopure compound 1 was isolated from the cultivation broth by ion exchange chromatography in high yield and was used as the starting material for the following reaction steps.

The syntheses started with an esterification of the carboxylic group of 1 (Scheme 1). Due to the electron withdrawing effect of the ester group, epoxidation of diol 2 and TBS-protected diol 4 using meta-chloroperoxybenzoic acid ( $m$-CPBA) took place exclusively at double bond $\mathrm{C} 3-\mathrm{C} 4.3,7$ The stereochemistry of the peroxide attack and the configuration of the resulting epoxide is directed by the functionality at $\mathrm{C} 2$. In the case of an allylic hydroxyl group, $m$-CPBA coordinates via hydrogen bonds and forces the C2-C3 cis-configuration of $3{ }^{8}$

Applying the same conditions to the protected diol $\mathbf{4}$ the bulky 2-siloxy group shields the $\alpha$-face of the cyclohexadiene plane hence the attack of the peracid takes place regiose-

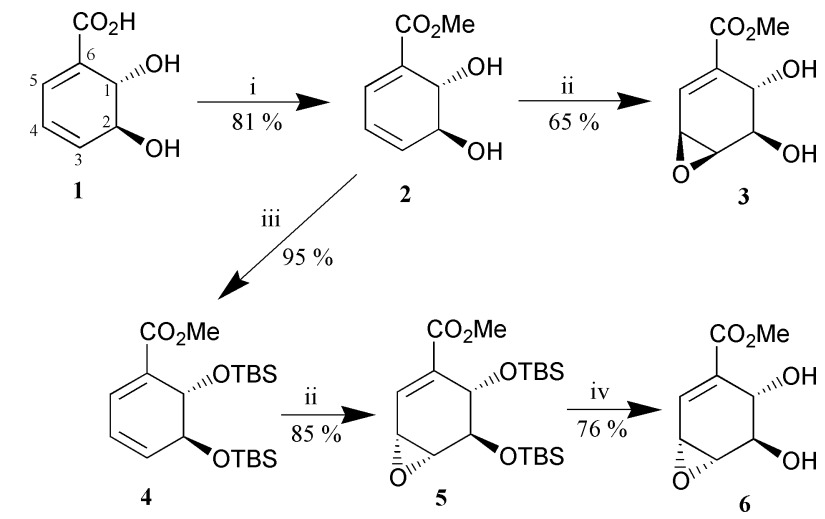

Scheme 1 Reagents and conditions: i, trimethylsilyl diazomethane $(2 \mathrm{~m}$ in hexane), $\mathrm{MeOH}, \mathrm{rt}, 6 \mathrm{~h}$; ii, $m$-CPBA, $\mathrm{NaHCO}_{3}, \mathrm{CH}_{2} \mathrm{Cl}_{2}$, rt, 3 h; iii, TBSOTf, $\mathrm{NEt}_{3}, \mathrm{CH}_{2} \mathrm{Cl}_{2}, \mathrm{rt}, 2 \mathrm{~h}$; iv, aqueous $\mathrm{HF}$ (40\%), acetonitrile, rt, 2 h.

lectively from the $\beta$-face. Compound $\mathbf{5}$ was obtained as a single diastereomer in $85 \%$ yield. ${ }^{3}$ The relative configuration of the oxirane ring in $\mathbf{3}$ and $\mathbf{5}$ with regard to the substituent at $\mathrm{C} 2$ was confirmed by ${ }^{1} \mathrm{H}$-NMR experiments. A coupling constant of $J_{1,2}$ $=7.9 \mathrm{~Hz}$ in $\mathbf{3}$ indicates the two hydroxy groups are in a diequatorial position due to the favoured twist conformation. On the other hand a $J_{1,2}$ coupling of $2.1 \mathrm{~Hz}$ shows the diaxial position of the protected hydroxy groups in $\mathbf{5}$. In addition, the relative configuration of $\mathbf{3}$ was proven by X-ray structure analysis (Fig. 1). ${ }^{9}$ Deprotection of 5 could be achieved by using hydrogen fluoride to give 6 in $76 \%$ yield.

The reduction of the ester group of $\mathbf{4}$ to the corresponding alcohol 7 was performed with diisobutylaluminium hydride (DIBAL-H) in $88 \%$ yield. ${ }^{10}$ Epoxidation of 7 with equimolar amounts of $m$-CPBA at low temperatures led to 8 in $91 \%$ yield. ${ }^{11}$ Reaction of 7 as well as 8 with an excess of the oxidizing agent at higher temperatures and prolonged reaction

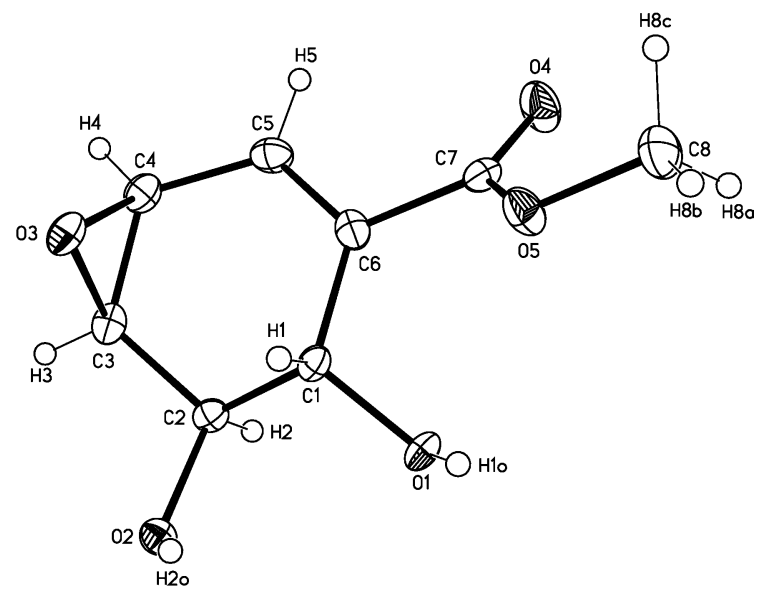

Fig. 1 Molecular structure of epoxide 3 showing the C2-C3 cisconfiguration. 


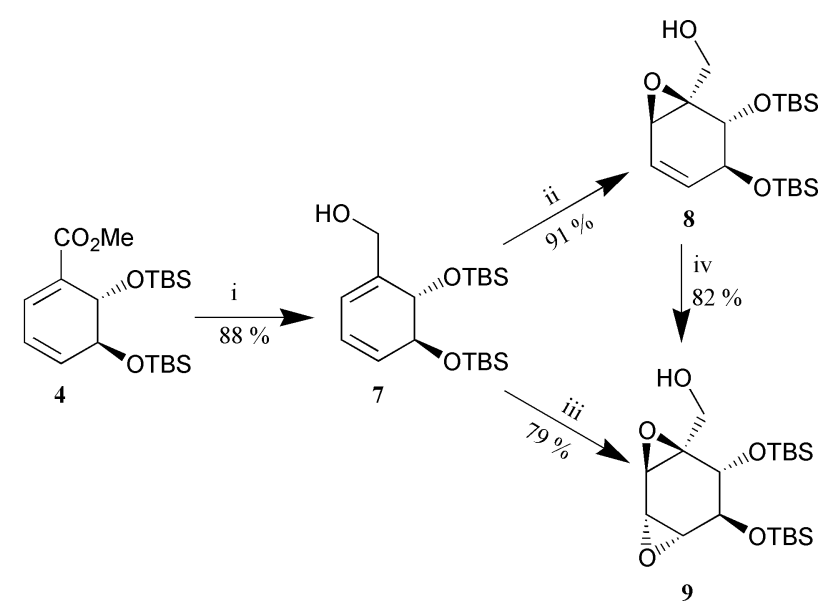

Scheme 2 Reagents and conditions: i, DIBAL-H, hexane, $0^{\circ} \mathrm{C}, 3 \mathrm{~h}$; ii, 1 eq $m$-CPBA, $\mathrm{NaHCO}_{3}, \mathrm{CH}_{2} \mathrm{Cl}_{2}, \mathrm{rt}, 3$ h; iii, 2.5 eq. $m$-CPBA, $\mathrm{NaHCO}_{3}$, $\mathrm{CH}_{2} \mathrm{Cl}_{2}, 50{ }^{\circ} \mathrm{C}, 16 \mathrm{~h}$; iv, 1.5 eq. $m$-CPBA, $\mathrm{NaHCO}_{3}, \mathrm{CH}_{2} \mathrm{Cl}_{2}, 50{ }^{\circ} \mathrm{C}$, $16 \mathrm{~h}$.

time resulted in the formation of bisepoxide 9 in high yields (Scheme 2). ${ }^{12}$

Compounds 8 and 9 possess already the core structure of entsenepoxide 12 and iso-crotepoxide 15. Benzoylation and subsequent cleavage of the siloxy groups with tetrabutylammonium fluoride (TBAF) led to $\mathbf{1 1}$ and $\mathbf{1 4}$, respectively. Acetylation of $\mathbf{1 1}$ and $\mathbf{1 4}$ quantitatively gave the stereoisomers of the natural products (Scheme 3 ). The yield over seven steps starting from $\mathbf{1}$ is $26 \%$ for ent-senepoxide $\mathbf{1 2}$ and $24 \%$ for isocrotepoxide (1,2,3,4-tetra-epi-crotepoxide) 15. In comparison, Shing et al. synthesized senepoxide starting from quinic acid in 17 steps. $^{13}$

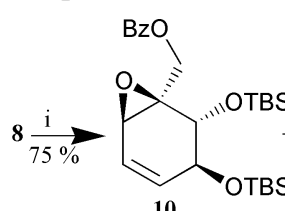

10

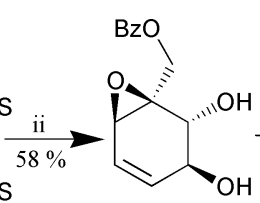

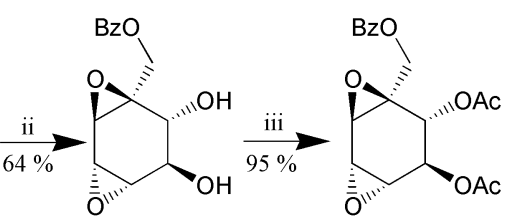

15
Scheme 3 Reagents and conditions: i, benzoyl chloride, pyridine, $-5{ }^{\circ} \mathrm{C}$, $6 \mathrm{~h}$; ii, 2.5 eq. TBAF, THF, $-78^{\circ} \mathrm{C} \rightarrow \mathrm{rt}, 2 \mathrm{~h}$; iii, acetic anhydride, pyridine, $0{ }^{\circ} \mathrm{C} \rightarrow \mathrm{rt}, 1 \mathrm{~h}$

Analytical data of ent-senepoxide 12 were identical with the literature data of Shing. ${ }^{13}$ Analytical data we found for 1,2,3,4-tetra-epi-crotepoxide $\mathbf{1 5}$ are identical with those White and coworkers reported for 3,4,5,6-tetra-epi-crotepoxide. ${ }^{14,15}$ However, evidence of the relative stereochemistry was given by $\mathrm{X}$-ray structure analysis of $\mathbf{1 4}$ that revealed the C2-C3 transconfiguration (Fig. 2). ${ }^{16}$

In summary, we developed a short and efficient synthesis of stereoisomers of the biologically active cyclohexane epoxides senepoxide and crotepoxide. The synthetic approach is based on the regio- and stereoselective epoxidation of microbially produced enantiopure 1. By choosing appropriate conditions and reasonable protecting groups it is possible to selectively introduce the oxirane moiety in senepoxide directly via peracid oxidation, contrary to other statements. ${ }^{13}$

All epoxides shown in this contribution, especially $3,6,8$ and 9, might also be ideal starting materials in the preparation of numerous other cyclitols and carbohydrate mimics.

M. N. thanks DAAD for financial support.

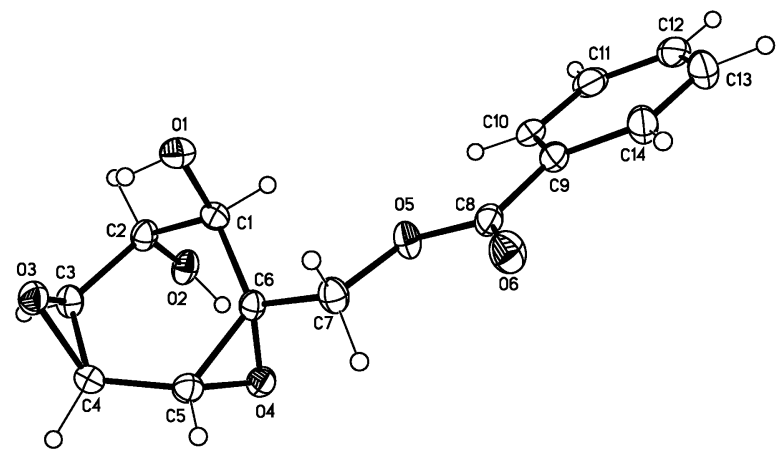

Fig. 2 Molecular structure of bisepoxide 14. The epoxide moieties are arranged in a trans-configuration to each other.

\section{Notes and references}

$\dagger$ The numbering scheme of the ring atoms here is deduced from the traditional view of cyclohexadienes as derivatives of aromatic compounds This scheme is different to that used in the equations and molecular structures.

1 M. Balci, Y. Sütbeyaz and H. Secen, Tetrahedron, 1990, 46, 3715 Carbohydrate Mimics. Concepts and Methods, ed. Y. Chapleur, WileyVCH, Weinheim, Germany, 1998.

2 T. Hudlicky, D. Gonzalez and D. T. Gibson, Aldrichimica Acta, 1999, 32, 35; and references cited therein.

3 B. M. Trost, L. S. Chupak and T. Lübbers, J. Am. Chem. Soc., 1998, 120 1732.

4 S. Ogawa and T. Takagaki, J. Org. Chem., 1985, 50, 2356; T. K. M. Shing and E. K. W. Tam, Tetrahedron: Asymmetry, 1996, 353.

5 T. Hudlicky, G. Seoane and T. Pettus, J. Org. Chem., 1989, 54, 4239; B. P. McKibben, G. S. Barnosky and T. Hudlicky, Synlett, 1995, 806; D. R. Boyd, N. D. Sharma, H. Dalton and D. A. Clarke, Chem. Commun., 1996, 45; D. R. Boyd, N. D. Sharma, C. R. O’Dowd and F. Hempenstall, Chem. Commun., 2000, 2151.

6 D. Franke, G. A. Sprenger and M. Müller, Angew. Chem., Int. Ed., 2001, 40, 555; $c f$. R. Müller, M. Breuer, A. Wagener, K. Schmidt and E. Leistner, Microbiology, 1996, 142, 1005.

7 S. Ogawa and T. Takagaki, Bull. Chem. Soc. Jpn., 1988, 61, 1413.

8 H. B. Henbest and R. A. L. Wilson, J. Chem. Soc., 1959, 1958; K. B. Sharpless and T. R. Verhoeven, Aldrichimica Acta, 1979, 12, 63; M. Freccero, R. Gandolfi, M. Sarzi-Amadé and A. Rastelli, J. Org. Chem., 2000, 65, 8948

9 Crystallographic data for 3: $\mathrm{C}_{8} \mathrm{H}_{10} \mathrm{O}_{5}, M=186.2, T=123 \mathrm{~K}$, monocyclic, space group $P 2_{1}$ (No.4), $a=8.6140(2), b=4.5655(1), c$ $=11.0991(4) \AA, \beta=112.512(2)^{\circ}, V=403.23 \AA^{3}, Z=2, D_{c} 1.53 \mathrm{~g}$ $\mathrm{cm}^{-3}, F(000)=196, \mu(\mathrm{Mo}-\mathrm{K} \alpha)=0.13 \mathrm{~mm}^{-1}, 8907$ reflections measured, 1418 unique which were used in all calculations, $w R 2\left(F^{2}\right)=$ 0.078 (all data), $R 1=0.029[I>2 \sigma(I)]$, flack parameter $x=0.5(10)$ CCDC 174631. See http://www.rsc.org/suppdata/cc/b1/b110420a/ for crystallographic files in .cif format.

10 N. M. Yoon and Y. S. Gyoung, J. Org. Chem., 1985, 50, 2443.

11 R. H. Schlessinger and A. Lopes, J. Org. Chem., 1981, 46, 5253; S. Ogawa, T. Toyokuni, M. Ara, M. Suetsung and T. Suami, Bull. Chem Soc. Jpn., 1983, 56, 1710; H. A. J. Carless and O. Z. Oak, Tetrahedron Lett., 1991, 32, 1671.

12 S. Ogawa and T. Takagaki, Bull. Chem. Soc. Jpn., 1987, 60, 800

13 T. K. M. Shing and E. K. W. Tam, J. Org. Chem., 1998, 63, 1547.

14 M. R. Demuth, P. E. Garrett and J. D. White, J. Am. Chem. Soc., 1976, 98, 634 .

$15{ }^{1} \mathrm{H}-\mathrm{NMR}$ data of 15: $\delta\left(\mathrm{CDCl}_{3}\right) 2.11(3 \mathrm{H}, \mathrm{s}), 2.16(3 \mathrm{H}, \mathrm{s}), 3.28(1 \mathrm{H}, \mathrm{s})$, $3.62(1 \mathrm{H}, \mathrm{s}), 3.66(1 \mathrm{H}, \mathrm{s}), 4.11(1 \mathrm{H}, \mathrm{d}, J 12.5 \mathrm{~Hz}), 4.73(1 \mathrm{H}, \mathrm{d}, J 2.5 \mathrm{~Hz})$, $5.18(1 \mathrm{H}, \mathrm{s}), 5.42(1 \mathrm{H}, \mathrm{s}), 7.47(2 \mathrm{H}, \mathrm{t}, J 7.6 \mathrm{~Hz}), 7.59(1 \mathrm{H}, \mathrm{t}, J=6.8 \mathrm{~Hz})$ $8.03(2 \mathrm{H}, \mathrm{d}, J=7.4 \mathrm{~Hz})$. The ${ }^{1} \mathrm{H}-\mathrm{NMR}$ data Shing et al. [Lit. 13] published for 3,4,5,6-tetra-epi-crotepoxide show significant differences to the data of 15 resp. White's 3,4,5,6-tetra-epi-crotepoxide.

16 Crystallographic data for 14: $\mathrm{C}_{14} \mathrm{H}_{14} \mathrm{O}_{6}, M=278.3, T=123 \mathrm{~K}$ orthorhombic, space group $P 2{ }_{1} 2_{1} 2_{1}$ (No.19), $a=8.8867(2), b=$ $11.7119(2), c=12.0177(3) \AA, V=1250.80 \AA^{3}, Z=4, F(000)=584$, $D_{c} 1.48 \mathrm{~g} \mathrm{~cm}^{-3}, \mu(\mathrm{Mo}-\mathrm{K} \alpha)=0.12 \mathrm{~mm}^{-1}, 24670$ reflections measured, 2206 unique which were used in all calculations, $w R 2\left(F^{2}\right)=0.056$ (all data), $R 1=0.022[I>2 \sigma(I)]$, flack parameter $x=-0.1(6)$. CCDC 174632 . 